\title{
Guilt by Association?
}

\author{
Michael J. Deem \\ Department of Multidisciplinary Studies and The Center for Genomic Advocacy \\ Indiana State University \\ http://mjdeem.weebly.com \\ michael.deem@indstate.edu \\ Grant Ramsey \\ Institute of Philosophy \\ KU Leuven, Belgium \\ http://www.theramseylab.org \\ grant@theramseylab.org
}

Recent evolutionary perspectives on guilt tend to focus on how guilt functions as a means for the individual to self-regulate behavior and as a mechanism for reinforcing cooperative tendencies. While these accounts highlight important dimensions of guilt and provide important insights into its evolutionary emergence, they pay scant attention to the large empirical literature on its maladaptive effects on individuals. This paper considers the nature of guilt, explores its biological function, and provides an evolutionary perspective on whether it is an individual-level or group selected trait. After surveying philosophical and psychological analyses of guilt, we consider which psychological mechanisms underlie the capacity to experience and act from guilt and whether they point to an emergence of guilt in early humans or to guilt having a longer phylogenetic history. Because guilt is a distinctively social emotion, we then examine its contemporary role in social and legal contexts, which may provide clues to its original biological function. Finally, we provide the outlines of two evolutionary explanations for guilt. We argue that group selection may have promoted the capacity to experience guilt, but that under certain conditions there may have been a positive individual selection force as well.

\section{Introduction}

Guilt plays an important role in human social life. Feelings of guilt motivate us to perform reparative behaviors when we have harmed others, they signal to others that we hold the proper attitude toward accepted social norms, and the anticipation of guilt can counteract impulses to 
shirk responsibilities, cheat cooperative arrangements, or violate communal rules. Recent evolutionary perspectives on guilt tend to focus predominantly on how guilt functions as a means for the individual to self-regulate behavior and as a mechanism for reinforcing cooperative tendencies (Frank, 1988; Joyce, 2006; Krebs, 2011). These accounts purport to show that guilt has a straightforward individual-level explanation insofar as it serves as a powerful counterweight to urges to violate group norms and motivates one to repair damage to intergroup relationships caused by one's actions. While these accounts highlight important dimensions of guilt and provide important insights into its evolutionary emergence, they tend to pay scant attention to the large empirical literature on its potential maladaptive effects on the individual.

Guilt can be costly due to some actions it may impel us to perform. For example, it can prompt us to confess our transgressions, despite the absence of witnesses. This can be a risky measure, sometimes incurring scorn, social exile, or other forms of punishment. Further, guilt often is associated with maladaptive psychological effects, including psychopathology (Averill, Diefenbach, Stanley, Breckenridge, \& Lusby, 2002; Bybee \& Quiles, 1998; Harder, 1995; Lindsay-Hartz, de Rivera, \& Mascolo, 1995; Luyten, Fontaine, \& Corveleyn, 2002). When these maladaptive effects are brought into relief, it becomes less clear from an evolutionary standpoint that guilt-prone individuals would do better than their guiltless counterparts. Now, just because an emotion may occasionally be psychologically maladaptive does not entail that it is not a biological adaptation; for instance, despite its connection to psychologically maladaptive behavior, the emotion of shame has been given plausible adaptationist explanations (Fessler, 2007). Perhaps something similar can be suggested for guilt: the capacity for guilt is an adaptation that facilitated and enhanced cooperation by strengthening social bonds, and any maladaptive effects are just by-products of a mismatch between this capacity and contemporary social conditions (O'Connor, 2000). But this explanation may rely too strongly on the ex ante assumption that maladaptive effects of guilt are not due to selective pressures. We contend that any adequate evolutionary explanation of guilt must also account for such psychological and potentially biologically maladaptive effects on individuals.

Guilt therefore presents us with an evolutionary puzzle. It seems that it is good for you that others are guilt-prone. And while there are clear ways in which guilt is good for groups of individuals, it is less clear that being guilt-prone is good for the individuals themselves. In exploring this puzzle, we consider the nature of guilt, explore its biological function, and provide 
an evolutionary perspective on whether it is an individual-level or group selected trait. We begin by surveying philosophical and psychological analyses of guilt before arriving at a clear conception of guilt (section 2). Against this background, we turn to the question of which psychological mechanisms underlie the capacity to experience and act from guilt, considering whether the evidence points to an emergence of guilt in early humans or whether guilt has a longer phylogenetic history (section 3). Because guilt is a social emotion, we then examine its contemporary role in social and legal contexts, which may provide clues to what its original function may have been (section 4). Finally, we provide the outlines of two evolutionary explanations for guilt (section 5). We argue that if the evolution of guilt preceded the origin of our species, group selection may have promoted the capacity to experience guilt, but if guilt is a recent evolutionary innovation, then the emotion may have an evolutionary origin based mostly—or even exclusively—on individual-level selection. ${ }^{1}$

\section{The Nature of Guilt}

In order to provide an account of the evolutionary origins of guilt, we must first have a clear conception of guilt as well as its expression and motivational profile. If guilt is not a discrete emotion, any attempt at an evolutionary account exclusively focused on guilt will be moot. We argue in this section that guilt is distinct from other dysphoric emotions, focusing on the contrast between guilt and shame, since the latter is the emotion most closely related to - and often conflated with — guilt. We show that these emotions can be distinguished conceptually and empirically according to how one views the self in experiences of shame and guilt, how each emotion is expressed, and the kinds of actions these emotions tend to motivate.

\subsection{Focus and Elicitors of Guilt}

While guilt and shame appear to be conceptually distinct, differentiating them empirically has proved a difficult task. Within clinical settings, for example, patients sometimes conflate shame and guilt, describing shame experiences in terms of guilt, and vice versa. In these and other cases, guilt often serves as an umbrella term when characterizing one's dysphoric affective state (Wicker, Payne, \& Morgan, 1983; Harder \& Zalma, 1990; Tracy \& Robins, 2006). A commonly held view among psychologists is that shame focuses on one's whole self or core identity while guilt focuses only on particular actions or behaviors for which the subject bears some 
responsibility (Baumeister, Stillwell, \& Heatherton, 1994; Tangney, Miller, Flicker, \& Barrow, 1996). The conceptualization of shame as self-focused and guilt as action-focused remains a dominant paradigm in psychological theory and clinical research. However, the neatness of this picture is purchased at the cost of neglecting important self-focused dimensions of guilt. Helen Block Lewis, who is often credited with developing this paradigm, presents a more fine-grained view of guilt: guilt involves less division or disorganization of the self than shame but nonetheless, like shame, has the self as part of its focus (1971, 1989; cf. Teroni \& Deonna, 2008). Because experiences of guilt focus on both the self and actions for which the self is perceived to be responsible, some researchers have conceived of guilt as focused on the self as agent (Barrett, 1995; Harmon-Jones, Amodio, \& Zinner, 2007). Experiences of guilt often include a diminished sense of self-worth and dissatisfaction with certain qualities of the self that may have contributed to the motivation or intention behind the action in question (Amodio, Devine, \& Harmon-Jones, 2007). Guilt seems to require some degree of self-appraisal—one must view oneself as responsible for an action or event in order for feelings of guilt to arise (Katchadourian, 2010). Thus, rather than characterize shame and guilt as self-focused and actionfocused, respectively, we suggest that it is more useful to conceive of shame as focused on the self qua object, and guilt on the self qua agent.

The disparate foci of shame and guilt show another way to distinguish them, namely, by their eliciting conditions. Guilt is generated from the perceived violation of some normative standard one has internalized or for which one antecedently cares. To experience guilt, one typically takes responsibility for having committed the violation in question, believing one could have done otherwise (Lewis, 1989; Lindsay-Hartz, de Rivera, \& Mascolo, 1995). Some psychologists and philosophers have also noted that experiences of guilt often include the unpleasant feeling that one's action or behavior is objectionable from the perspective of others, that one is unjustified and defenseless before such objections, and, perhaps, that one is deserving of scorn and punishment (Moore, 1987; Baumeister, Stillwell, \& Heatherton, 1994; Joyce, 2006). Unlike guilt, shame need not be associated with some action or behavior for which one takes oneself to be responsible. Shame arises from one's perceived shortcomings in living up to either an ideal one has adopted for oneself or to the expectations of others (Keltner \& Buswell, 1996). There is some debate in the literature on how effectively one can distinguish guilt and shame based on eliciting conditions alone (Tangney, 1996; Tracy \& Robins, 2006); however, Keltner 
and Buswell's (1996) wide-ranging study on the elicitors of shame and guilt shows that while the two emotions share several antecedents, their most common antecedents are distinct.

\subsection{Signaling Guilt}

Guilt and shame are also distinguishable by associated external expressions. What actions do persons tend to perform when experiencing guilt or shame? Action tendencies of shame range from attempts to conceal one's failure or flaw, to more extreme acts of social withdrawal (Barrett, 1995; Tangney, 1995). Guilt, in contrast, motivates remedial actions of restitution and atonement, particularly toward those who were harmed by one's behavior (Lindsay-Hartz, de Rivera, Mascolo, 1995; Katchadourian, 2010), as well as verbal gestures such as confessing to, or apologizing for, a violation. Feeling guilty can even motivate self-punitive actions, such as turning oneself in and accepting external punishment for wrongdoing, or self-inflicted harm under the assumption of a need for penance.

In addition to distinct action tendencies, we might wonder whether shame and guilt have stereotyped facial or bodily expression. Clinical research and empirical studies suggest that shame is reliably linked to both. Characteristic facial indicators of shame include gaze aversion and blushing in the presence of others (Lewis, 1971; Barrett, 1995). Common bodily displays of shame include slumping of the shoulders, smaller posture, and lower vocalic patterns (Scherer, 1986; Barrett, 1995). Studies have shown that observers can reliably identify experiences of shame in others based on such expressions (Keltner, 1995; Keltner \& Buswell, 1996). In contrast, it is not clear that guilt involves any characteristic facial or bodily expression. While some researchers have suggested that guilt feelings are often accompanied by elevated heart rate and irregular respiration (Ekman et al., 1983; Barrett, 1995), studies have not isolated reliable facial or bodily indicators of guilt. For example, Keltner and Buswell (1996) found that observers could not reliably identify guilt in photos of facial displays showing candidate expressions of guilt, whereas they could with shame and embarrassment. In a study using actors to perform bodily movements thought to communicate emotional states to observers, Wallbott (1998) discovered that while many emotions were reliably conveyed to and identified by test subjects, guilt was not among them. These studies appear to confirm the growing consensus that there is no reliable, stereotyped display of guilt (Keltner \& Harker, 1998; Fessler \& Haley, 2003; Kochanska \& Aksan, 2006; Ferguson, Brugman, White, \& Eyre, 2007). This has led several 
researchers to conclude that signaling of guilt is primarily verbal and behavioral, communicated voluntarily by word (e.g., apology) or action (e.g., attempts at reparation or expiation)

(Malatesta, 1990; Zahn-Waxler \& Kochanska, 1990; , 1995).The foregoing considerations of the difference between guilt and shame are useful for arriving at a clearer conception of the emotion of guilt. Guilt is a negative affect arising from perceiving that one has violated a normative standard. Its focus is on the agential self and the action that counts as a transgression. Guilt typically involves an acknowledgment of one's responsibility for wrongdoing and the feeling of being defenseless against the anger and indignation of others, and of having no right to be spared of these negative emotions or punishment. Guilt tends to motivate reparative acts, such as apology, confession of wrongdoing, turning oneself in, or even costly endorsement of external punishment or self-inflicted harm.

It is clear on both empirical and philosophical grounds, then, that guilt is a unique emotion, distinct from shame and other dysphoric emotions. ${ }^{2}$ Seeking an evolutionary origin for guilt is therefore justified and may shed considerable light on guilt's nature and function. ${ }^{3}$ The first step of such an account is to ask which psychological mechanisms serve as enabling conditions for experiencing guilt, a task to which we now turn.

\section{Ontogenetic and Phylogenetic Considerations}

Investigating the evolution of guilt in humans involves consideration of comparative research on related or similar traits in other primates. In this section, we briefly consider the psychological mechanisms commonly taken to be required for, or to emerge codevelopmentally with, experiences of guilt in humans. This will help in determining whether there are discernible evolutionary antecedents to guilt in other primates.

\subsection{Psychological and Neuroscientific Data}

Empirical research on guilt experiences within developmental psychology and neuroscience reveals them to be the product of complex cognitive processes. Several studies on the development of guilt in children show that guilt-proneness and the capacity to recognize expressions of guilt in others emerge relatively late in childhood, well after children have developed capacities for experiencing and recognizing many other emotions, including sadness, happiness, and shame (Harris, 1989; Zahn-Waxler \& Kochanska, 1990; Barrett, 1998). Harris 
(1989) and Ferguson, Stegge, and Damhuis (1997) found that children first begin to exhibit the capacity to recognize appropriate situations for feeling guilt no earlier than the age of seven and as late as the age of ten, only after they are capable of attributing to themselves responsibility for actions and evaluating their actions and those of others according to normative standards. These findings are consistent with other empirical studies in developmental psychology that locate the emergence of the capacity for guilt subsequent to the emergence of capacities for complex representations of the self and distinguishing the self from others, for attributing to oneself causal responsibility for one's actions and their consequences, and for empathic concern (Zahn-Waxler \& Kochanska, 1990; Kochanska, Gross, Lin, \& Nichols, 2002; Lagattuta \& Thompson, 2007). These studies show that the capacity to experience guilt is either dependent on, or closely associated with, other cognitive benchmarks that are met at earlier stages of human childhood development. The extant developmental research, therefore, suggests that guilt is a cognitively complex emotion in humans, emerging after a number of psychological capacities have developed.

Recent work in neuroimaging has shown that several parts of the brain are active during experiences of guilt, including the superior temporal sulcus and anterior prefrontal cortex (Shin et al., 2000; Takahashi et al., 2004; Moll, de Oliveira-Souza, Zahn, \& Grafman, 2008). Through EEG recording, Amodio, Devine, and Harmon-Jones (2007) discovered a unique link between increased guilt and reduced left-frontal cortical asymmetry, which they found did not similarly obtain in experiences of anxiety, sadness, and other-directed negative affects. The reduced asymmetry between left- and right-frontal cortical activity during guilt experiences suggests that guilt is associated with both approach and withdrawal orientation, motiving a complex sequence of self-regulatory and reparative behaviors. These results are consistent with more theoretical neurobiological views that take guilt to be an effect of the integrated operation of subcortical and neocortical processes, enabling highly cognitive activities such as taking the perspective of others, looking backward at one's transgression, and planning and executing long-term responses to wrongdoing (Panksepp \& Biven, 2012).

These empirical studies in developmental psychology and neuroscience thus show guilt in humans to be a psychologically complex emotion dependent on, or developmentally coemergent with, a number of cognitive processes. Given the psychological complexity of guilt, we should ask whether experiencing guilt is uniquely human, since, as we argue below, how 
recently guilt evolved is crucial to understanding the kinds of selection pressures that likely shaped the emotion.

\subsection{Guilt in Other Primates}

Other primates appear to possess at least some of the capacities that are required for or are closely associated with guilt experience in humans. For example, researchers point to evidence that some nonhuman primates possess something like a theory of mind (Cheney \& Seyfarth, 2007; Call \& Tomasello, 2008), are capable of self-recognition (Kaneko \& Tomonaga, 2011), and even internalize some social rules (de Waal, 1996). While there may be evidence for these capacities in other primates, is there evidence that nonhuman primates experience guilt?

Perhaps the best indication would be cases in which other primates appear to discriminate certain social rules and display appeasement behavior whenever they breech those rules and subsequently encounter a dominant conspecific. A well-known example is Coe and Rosenblum's (1984) experimental observations of subordinate macaques' mating behavior. When the dominant male macaque was present but contained by the experimenters, the subordinates did not attempt to mate with females. In the dominant male's absence, however, the subordinates initiated mating displays and behaviors. Upon the dominant male's return, the subordinates behaved more submissively toward him than they did prior to the surreptitious mating. Coe and Rosenblum concluded that macaques recognize violations of those social rules and accordingly perform appeasement behaviors. Boehm (2012) relates a similar example from his time studying chimpanzees in Gombe. After copulating with a female, adolescent male chimps would furtively glance at the dominant male, putting on displays of appeasement despite having kept the act out of sight. De Waal (1996) interprets such behaviors as expressing a concern about the rule enforcer's reaction even when he is not present. De Waal suggests that this concern may indicate the evolutionary starting point among primates for the capacity for shame and guilt. Boehm, however, explains the subordinate males' behavior in terms of fear of discovery and subsequent punishment rather than of recognition of rule-violation. In either case, violations of primate troop rules followed by appeasement displays do not themselves provide sufficient evidence to conclude that some nonhuman primates have guilt-like experiences.

Fessler and Gervais (2010) leave open the possibility that other primates are equipped with a guilt-like mechanism that may explain reconciliation behaviors toward conspecifics. 
However, they argue that humans possess a unique capacity for what they call "normative guilt," which they understand to be elicited by violating norms in the absence of an audience. In place of an actual person or group that their transgressions harm, humans often form mental representations of culturally constructed agents or social groups before whom reparations and atonement ought to be performed. Fessler and Gervais suggest that the complexity and social nature of these representations reveal a significant gap between human emotional capacityparticularly with respect to guilt- and that of other primates.

Does the psychological complexity and late developmental emergence of guilt in humans then suggest that the emotion is not present in closely related primates? Some philosophers answer this question in the affirmative (e.g., Joyce, 2006). We agree that the foregoing primatological and anthropological considerations suggest that the available data, at best, are inconclusive as to whether other primates experience guilt or some form of proto-guilt. However, the observed behavioral homologies between humans and some other primates do not permit us to rule out altogether a similar, guilt-like psychological mechanism in other primates. ${ }^{4} \mathrm{We}$ therefore consider below both scenarios - a phylogenetically early and a late origin of guilt - in forming our conclusion about how guilt might have evolved. Because there are grounds for thinking that guilt is a uniquely human emotion, arising from phylogenetically novel interactions between intricate cognitive machinery and complex social arrangements, we will investigate in some detail below what role guilt plays in human social structures, in which contexts it is adaptive, and who benefits from individuals being guilt-prone. This will allow us to develop a scenario for a uniquely human evolution of guilt, which we can contrast with its phylogenetically deep alternative account.

\section{Current Effects of Guilt}

Is there an individual-level payoff for feeling guilty in particular circumstances? There are three main ways that this question has been addressed in the literature. One is by constructing mock trials and surveying participants' views about the punishment that the accused should receive. Another is through an examination of real trials and legal procedures in an attempt to see what role guilt plays for offenders and the legal determination of their fate. Third, these questions have been addressed through study of individuals outside the legal arena to see what role guilt plays in everyday life. We will address each of the three approaches in order to arrive at a broad 
understanding of how guilt functions in contemporary social contexts.

Before proceeding with an examination of the legal literature on guilt, three caveats are in order. First, 'guilt' is legally defined as being responsible for a criminal or civil offense. The moral emotion of guilt, though it might often be felt upon being guilty of an offense, bears no necessary link to the legal sense of guilt. To keep the two senses of 'guilt' distinct, we will use the term 'guilt $\mathrm{L}_{\mathrm{L}}$ ' to denote guilt in the legal sense, while 'guilt' will denote the emotion. Second, the legal literature often uses the term 'remorse' to denote expressions of guilt. We adopt this convention in our discussion here. Third, if there are no stereotyped bodily indicators of guilt (see section 2.2), then those studies discussed below that use stereotyped criteria for remorse (crying, downcast eyes, etc.) will have inherent problems, since they may assume that these displays typically are expressions of guilt.

\subsection{Guilt in Mock Court Cases}

To better understand the role of remorse in sentencing and punishment, let's break our discussion of mock court cases into two parts: (1) the determination of guilt , and (2) the determination of punishment. What role do expressions of remorse play in the determinations of guilt $\mathrm{L}_{\mathrm{L}}$ ? The impact is often negative, and while being responsible for an outcome often leads to remorse, bad outcomes for which one is not responsible can also lead to remorse (Bornstein, Rung, \& Miller, 2002; Jehle, Miller, \& Kemmelmeier, 2009). There is a key variable that is important in determining the effect of remorse: the context and timing of the display of remorse. One might exhibit remorse at the time of the incident or the time of the trial, for instance. Expressing remorse at the time of the incident implies guilt $t_{\mathrm{L}}$ more strongly than exhibiting remorse subsequently, at the trial (Bornstein, Rung \& Miller, 2002). But any remorse expressed at any time postincident may be interpreted as a sign of guilt $\mathrm{L}$.

Now consider individuals who have already received a guilty verdict or who are presumed guilty. What are the costs and benefits for expressing guilt? For one, the punishment the accused receives will generally be reduced (Gold \& Weiner, 2000; Robinson, Smith-Lovin, $\&$ Tsoudis, 1994; Garvey, 1998). The degree to which the remorse expressions modulate punishment is affected by a number of factors. If the incident is not all that severe, if it involves a significant degree of chance, or if it is otherwise indicated that the behavior does not represent the perceived moral character of the accused, then remorse is apt to result in a decrease of 
punishment. If, on the other hand, the behavior is severe or does not involve significant elements of chance, then it is more apt to be viewed as the product of the accused's character. When the

behavior is viewed as stemming from the putative character of the accused, the punishment may be lowered, but it will not be lowered to the degree that it would were it not perceived as part of the accused's character.

In sum, remorse often increases the chance that one is found guilty $y_{L}$ of a transgression in mock trial cases, but it tends to reduce the punishment of one already accused or presumed guilty . Because remorse cuts both ways, the answer to the question of whether it is good overall to express remorse will be determined by the strength of the factors discussed above, especially the degree to which the guilt $t_{\mathrm{L}}$ of the accused is in question. For example, expressing remorse in a small community, or where one is caught red-handed, is probably on average more beneficial for the accused than expressing remorse in a case where the evidence is tenuous and/or the accused is completely unknown to the jury. This of course places the wrongly accused in a bind (Weisman, 2004). They may naturally lack remorse due to their lack of guilt $\mathrm{L}$, and while a lack of remorse may serve as evidence for their lack of guilt $t_{\mathrm{L}}$, failing to express remorse has a strong chance of backfiring.

\subsection{Guilt in Law and Punishment}

The mock jury cases clearly show that we wish to punish remorseless offenders more than remorseful ones. And there are numerous actual cases in which a lack of remorse has led to a prolonged sentence. Displays of remorse appear to be more helpful for a first-time offender than for a recidivist, perhaps because the first time offender is more credible (Harrel, 1981). And remorse plays a greater role for mitigating the punishment of less vicious crimes than extremely vicious ones (Eisenberg, Garvey, \& Wells, 1998). We thus wish to-and often do-punish the remorseless more severely, but why?

One suggestion is that remorselessness correlates with recidivism, though the empirical support linking the two is not as strong as one might imagine (Cox, 1999). Studies that have looked for a link between remorse (or related emotional displays, like that of empathy) and lower chance of recidivism often come up short of establishing a link. For example, Hanson and Bussière (1998) couldn't find any evidence for a link between displays of empathy toward the victim and lower recidivism rates for sexual offenders. 
A lack of evidence for a link between remorselessness and recidivism in these studies, however, is not proof that no link obtains. It could be that the right studies have yet to be conducted. In fact, Hosser, Windzio, and Greve (2008) interviewed 1,243 prisoners during their incarceration and found that feelings of guilt early in their prison terms were negatively correlated with recidivism, whereas feelings of shame were positively correlated with recidivism. This shows both that remorse may in fact indicate a reduced probability of recidivism as long as it is a genuine display of guilt, and that there are drawbacks with using 'remorse' as an umbrella term for feeling bad subsequent to committing an offense, since if guilt and shame pull in opposite directions, a failure to distinguish them will lead one to fail to discover their causal role. This study also points to the importance of distinguishing genuine feelings of guilt from mere putative expressions of remorse. Offenders will generally use remorseful displays strategically prior to and during trials, and such displays may thus carry little information about feelings of guilt, whereas this study, which surveyed prisoners posttrial (where admissions of guilt/shame presumably do not affect their fate), does a better job at discovering the emotional lives of the incarcerated. Other recent studies also show a significant inverse relation between recidivism and moral cognition as well as between recidivism and the experience of moral emotions (with the former effect being larger than the latter) (Van Vugt et al., 2011). It also appears that expressing remorse in conjunction with an apology can help bring about forgiveness and closure for the victim and/or their family and friends (Bibas \& Bierschbach, 2004; Orleans \& Gurtman, 1984).

In sum, feelings of guilt negatively correlate with recidivism rates. This provides justification for treating differently those who express genuine guilt and points to important selection pressures in the evolution of guilt. To expand our understanding of the role of guilt, let's now move outside the confines of the legal system and consider the question of what the consequence of being guilt-prone is for individuals and the groups to which they belong.

\subsection{Effects of Being Guilt-prone}

Individuals who score high in guilt-proneness, as measured by the Guilt and Shame Proneness Scale tend to exhibit less counterproductive and delinquent behaviors than those who are less guilt-prone (Cohen, Wolf, Panter, \& Insko, 2011; Cohen, Panter, \& Turan, 2012). Similarly, Malti and Krettenauer (2013) conclude that there is a positive relation between feelings of guilt 
and prosocial behavior. Svensson, Weerman, Pauwels, Bruinsma, and Bernasco (2013) found that the anticipation of feelings of guilt serves as a deterrent to committing offenses. There is also some evidence that being guilt-prone makes one more apt to take on the role of a leader, and guilt-prone individuals are more likely to be selected for leadership positions (Schaumberg \& Flynn, 2012). But given that one is prone to guilt, what effect does experiencing guilt have for subsequent behavior? Comparing guilt and shame, Silfver (2007) found that guilt is more likely to lead to reparative prosocial behavior than shame. And it appears that feelings of guilt make one more apt to perform altruistic acts (Regan, 1971) and to be more compliant (Carlsmith \& Gross, 1969).

There appears to be an interesting interaction between reputation and expressions of remorse. Individually, exhibiting remorse or having a good reputation is sufficient for regarding the individual as likable, but only the combination of remorse and a good reputation was sufficient to mitigate punishment (Darby \& Schlenker, 1989). Those with a bad reputation may be regarded as feigning remorse merely to reduce their punishment, while those with a good reputation are apt to have their remorse judged to be genuine.

In sum, it appears to be good when others are guilt-prone: it prevents their inefficient, counterproductive, or deleterious behavior, and prompts reparation and altruism. There is thus a clear benefit to individuals for belonging to a group composed of guilt-prone individuals. But many of the characteristics that make it individually good to belong to such a group may also provide benefits to the group itself such that groups composed of guilt-prone individuals should outperform other groups not so composed, making guilt-proneness good at the group level. In order to assess the group-level costs and benefits of being composed of guilt-prone individuals, as well as the individual-level consequences of being guilt-prone, we need to synthesize the full array of results from the previous sections, which we do in the following section.

\section{Guilt by Association?}

The previous sections evince the complex role that guilt plays at the individual and group levels, and we will now consider what their results imply about the evolution of guilt. We will take ancestral humans as our starting point, since, as we saw in section 3, there is reason to think guilt may have evolved relatively recently and may be unique to humans. We are not foreclosing an earlier origin of guilt, but instead are taking what we understand to be the more plausible 
option - guilt arising within the human lineage. We return to the consideration of an earlier origin when we present our conclusion. Since we are taking data from contemporary social contexts and speculating about what occurred in our deep evolutionary past, the conclusions we arrive at in this section are tentative. Nevertheless, we are confident that the data point to one or more plausible evolutionary scenarios.

\subsection{Group-Level Benefits of Guilt}

Group selection theory has had a complex and highly contested history (Okasha, 2006). Prior to the mid-1960s, group selection explanations were part of a standard explanatory toolbox - traits, it was thought, could be explained by pointing out that they are good for the group or good for the species. With the publication of Williams (1966), group selection explanations received a devastating critique, leaving such explanations proscribed in biology through the 1970s and 1980s. Group selection explanations have recently regained some legitimacy, particularly through the work of philosophers and biologists on the evolution of altruism and human cooperation (Sober \& Wilson, 1998; Sterelny, 2003). In what follows, we will not directly engage with this debate, but will assume that group selection is explanatorily admissible and can be cogently modeled.

To see whether a case can be made that being composed of guilt-prone individuals (henceforth GPIs) is a group-level benefit, consider the following benefits, discussed above in sections 2 and 4 :

A. GPIs are more efficient. Since it is a group-level benefit to be composed of efficient members, it is a benefit to have members who are guilt-prone.

B. GPIs are more likely to reveal their offenses. This is beneficial for groups because it will lead to greater exposure and punishment of offenders. This has the benefit of reducing recidivation rates of offenders and will also help deter other individuals from committing like offenses.

C. GPIs are more likely to reveal that they know they have committed a wrong. For many offenses, the identity of the offender will not be a mystery. In such cases, guilt will not be needed in order to reveal the identity of the offender. But in such cases, guilt nevertheless 
has a positive role to play. If the individual who committed the wrong expresses feelings of guilt, then group members gain the information that the offender knows its actions to be wrong and will therefore not be apt to recidivate.

D. GPIs exhibit a greater degree of prosocial and altruistic behavior. If it is better for a group to be composed of highly prosocial and altruistic individuals, as it seems to be, then the link between guilt-proneness and prosociality/altruism implies that GPIs are good for the group.

E. GPIs are deterred from offending. GPIs who recognize themselves as guilt-prone, and know the psychological pain associated with guilt and/or the way that guilt leads one to reveal their offenses, will be less apt to commit an offense than a non-GPI.

\section{F. GPIs are more apt to be chosen as leaders and to take on leadership roles. Having} GPIs in leadership roles is generally beneficial for the group because characteristics A-E are especially important in leadership roles, where the stakes are high.

Each of these features of GPIs has a clear group benefit. But before we conclude that there is net positive group selection for groups composed of GPIs, we must first ask whether any of these features of GPIs have negative effects on the fitness of groups.

Of the above features of GPIs, the two that are most apt to have a negative effect on the group are the increased propensity to be altruistic, prosocial, and hesitant to commit offenses (D and E). Although this will generally be good within the group, it will not always be beneficial between groups. If groups of individuals are competing with one another, having GPIs indiscriminately dispense benefits to others independently of which group they belong to may be detrimental to their group. Individuals will occasionally be called upon to fight or harm others, and if being guilt-prone interferes with this, it can cause group-level problems. One way around this, however, is to conceptualize the norms, one's group members, and outsiders in such a way that guilt is elicited only from harming members of one's own group. At an extreme, one could consider members of one's group to be human while classifying outsiders as nonhuman, thus decreasing the chance that one will feel guilty subsequent to violent acts toward the latter. It is 
notable that some tribal groups have similarly constrained domains of those whom they consider to be humans, that patriotic fervor against foreigners can be fueled by referring to them as "evil" or "animals," and that modern militaries strategically dehumanize the enemy to get their soldiers to fight more effectively. Thus, although GPIs can impede the group, there are effective ways for groups to harness the categories of $u$ and them to sequester the guilty feelings for one's group members. Given this, there are compelling reasons to think that the benefits groups gain from containing GPIs outweigh the costs, and that groups with GPIs will therefore outperform groups lacking GPIs.

Does this mean that we now have a story for the origin of guilt as a group selected emotion? We do have good reason to support the claim that guilt has a net positive effect on groups. If group selection models are tenable, then we can thus infer that guilt arose at least in part due to group-level selection processes. But before we can classify it strictly as a product of group selection, we must consider whether there is a compelling individual-level selection account of the origin and persistence of guilt.

\subsection{Individual-Level Benefits of Guilt}

Although there is strong evidence for a positive net selection pressure at the group level, the situation is not as clear at the individual level. Let's begin by considering some reasons why it may be individually maladaptive to be a GPI. First, it is easy to see that B, D, and E can be maladaptive: it can be bad for individuals to reveal their offenses (B), especially if their punishment will be severe. Although it is often beneficial to be the recipient of prosocial behavior (D), it may be individually costly to perform such behavior. Finally, while it is beneficial to be deterred from offending (E), especially when one is likely to be caught, it can be individually advantageous to lack guilt. Even if lacking guilt can result in one being punished more often, there may be significant benefits to be reaped when one is not caught. Moreover, there is some evidence that non-GPIs will be able to shorten the duration of punishment more successfully than GPIs. Porter et al. (2009), for example, found that psychopathic offenders had a success rate for their applications for conditional release that was 2.5 times that of nonpsychopathic offenders. Psychopaths, lacking the burdens of guilt, are able without compunction to say anything they need to in order to get released from prison. The guilt-prone individuals are not so unrestricted in their pleas and are not as successful with their conditional 
release. The psychopath's success is especially striking in light of the fact that psychopathy is one of the strongest predictors of recidivism (Leistico, Salekin, DeCoster, \& Rogers, 2008).

Now let's consider in what ways it might be individually advantageous to be a GPI. Acting with efficiency (A) likely will be good for individuals, as they will be more apt to be held in high esteem. Similarly, as we saw in section 4, if an individual is known to have committed an offense, admitting that they recognize the wrong they committed (C) likely will be beneficial. And if being a GPI makes such an admission more probable and more sincere, then being guiltprone may be advantageous. Finally, since there is evidence that GPIs naturally take on leadership positions - and are more likely to be chosen as leaders - if there is a selective advantage for leaders, then this is further reason to think it is advantageous to be guilt-prone.

Let's take stock. Of the six features of GPIs listed above, three seem to be individually maladaptive, while three appear adaptive. It looks like we are at a standoff with the net individual selection pressure at best being weak and without a clear direction. Is this the best we can do? Although we will conclude that the jury may still be out for the individual-level selection case, we think that some of the features identified as individually maladaptive (B, D, and E) may have an adaptive side. To see this, we will consider an argument for the adaptive nature of guilt provided by Robert Frank.

\subsection{A Problem for the Commitment Model}

We saw above that B, D, and E may be maladaptive: an individual who is likely to reveal their offenses (B), perform acts of altruism (D), or is deterred from offending (E) is apt to be less fit than an individual not so inclined. But is there a way that B, D, and E may have a net positive selective effect on individuals? To see how this might be the case, let's consider Robert Frank's $(1988,2001)$ commitment account of the strategic role of the emotions.

According to Frank, some of our emotions play a strategic role in cooperative relations, having evolved to solve what he calls "the commitment problem." These moral emotions have a stabilizing effect on social arrangements because they motivate one to cooperate within joint ventures that yield benefits to most of the parties in the long run, and they signal to the other parties that one is disposed to cooperate rather than cheat or defect at the expense of the group. A function of guilt, specifically, is to counteract the attraction of immediate payoffs that come from defecting from a joint enterprise by representing and incentivizing future payoffs that come from 
cooperation. Of course, to reap the benefits of cooperative arrangements, parties must first be able reliably to recognize those individuals disposed to cooperate and those who might defect out of self-serving interests. In addition to good reputation, parties look for statistically reliable clues for proneness to moral emotions in the facial expressions of others, which helps them discern with whom to cooperate. Frank contends that moral emotions came under selection pressure to play this signaling role. ${ }^{5}$

For guilt to have been selected to help solve the commitment problem on Frank's account, it must (a) help motivate cooperative behavior and (b) be associated with a reliable, hard to fake bodily expression or signal. There is some empirical support for (a). As we saw above, GPIs are less likely to commit offenses (E) and are more likely to reveal offenses that they have committed. Furthermore, Ketelaar and Clore (1997) and Ketelaar and Au (2003) found that experimentally manipulated experiences of guilt during social bargaining games is associated with increased cooperation among individuals who had committed one or more transgressions against their partner and among individuals who tended initially to be uncooperative. In another study, Amodio, Devine, and Harmon-Jones (2007) found that guilt arising from transgressions of prejudice predicts an increased interest in prejudice-reducing and reparative behavior.

Now consider Frank's second criterion. There is an obvious problem with (b), as we have noted in section 2: guilt does not have a characteristic facial or bodily expression. What sort of facial expressions does Frank associate with guilt? He claims that a "furtive glance and difficulty making eye contact," as well as blushing triggered by self-consciousness, are typical symptoms of guilt (1988, p. 126). However, as we noted above, psychologists tend to associate these facial expressions more with shame (and, occasionally, embarrassment) than with guilt. Does Frank then conflate guilt and shame? It is certainly possible that he does with respect to facial expression, and the lack of stereotyped expressions for guilt may undermine his view.

The benefit of Frank's view for the individual-level selection story is that if one can reliably identify GPIs, then one will disproportionally select them for mutually beneficial cooperative ventures. And if GPIs are chosen and the non-GPIs tend to be left out, then it may be individually advantageous to be a GPI. Behaviors that are costly indicators of being a GPI (such as B, D, and E) may be offset if they will purchase admission to highly beneficial cooperative relationships. It seems, then, that there is good reason to think that Frank's account of guilt is 
only partly flawed. Because guilt does not have a universally recognized facial expression, it could not have been selected to solve the commitment problem in the way that Frank conceives it.

However, there may be other ways to reliably identify GPIs. While Frank is right that reputation is not always a good indicator of trustworthiness, the consilience of distinct sources of information about an individual's character can provide a good picture of their emotional dispositions. If one (1) has information about an individual's reputation, (2) has directly observed their behavior when acting with themselves and others, and (3) has heard them discuss their dealings with others, then it is going to be relatively easy to know how guilt-prone the individual is. And knowledge of this sort was unlikely to be out of reach for the small groups in which guilt presumably evolved. Moreover, acts of reparation, such as confession to wrongdoing, remediating harm, and self-inflicted penance, can be risky and costly for the individual. Supposing such behaviors constitute signals of guilt, then they may serve as reliable, hard to fake signals on account of the costs, time, and sustained motivation they require of the individual.

If this is true, then there is strong reason to believe that individual selection helped drive the evolution of guilt. ${ }^{6} \mathrm{We}$ are left, then, with the conclusion that guilt was likely selected for at both the individual and group levels, and the presence and form of the emotion is due to the composite strength of these selection pressures.

\section{Conclusions}

We began with an evolutionary puzzle: why did guilt evolve if it is not obviously a good thing for the individual to be guilt-prone? We found that the first step in answering this question is to try to get clear on the nature of guilt and account for both its adaptive and its maladaptive effects. This showed that the answer is not a simple one; there is no obvious single candidate cause for the origin and maintenance of guilt, but instead two candidate causes - group and individual selection - each of which enjoys some plausibility. Group selection provides an almost uniformly positive selection pressure for groups of guilt-prone individuals, though it is not clear that the group selection vector could have been sufficiently strong to account for the evolution of the emotion. While group selection can promote guilt-proneness in the absence of language and culture, it is not clear that individual selection could have a net positive selection force without 
language and culture. The reason for this is that language and culture allow individuals to tell stories about how they felt and acted due to their own or other's transgressions. Additionally, language enables social transmission about reputations and dramatically increases the available information about the guilt-proneness of others in one's group. Without such information, reliably choosing guilt-prone individuals for cooperative ventures would be all but impossible, especially since there are no stereotyped, reliable bodily and facial expressions of guilt.

The state of the research, therefore, does not overwhelmingly support either an individual- or group-level account. But it does support the following pair of conditionals. If guilt is phylogenetically widespread (occurring in nonhuman primates and perhaps other related taxa), then it probably evolved as a response to group-level selection pressures. If instead guilt evolved recently within the hominin lineage, then individual-level evolutionary accounts could explain the evolution of guilt.

This pair of conditionals suggests a host of empirical and theoretical avenues of enquiry that bear on the story of guilt. More work on the individual- and group-level models of guilt is needed to fully assess the strength of the selection pressures. (For example, is the space of parameter values for a group selection account large enough for us to accord group selection sufficient, enduring power to produce a guilt-prone phenotype? Can an individual-level model account for the maladaptive behaviors that guilt induces?) And more work on the comparative biology of guilt will help resolve the debate about whether guilt is confined to the hominin lineage. If guilt or something akin to guilt-proneness is not unique to humans, then evolutionary scenarios requiring complex social cognition (e.g., tracking reputation, being aware of social norms and discriminating transgressions) are not going to be available to explain how guilt arose in primates. The evolutionary story of guilt is thus far from being fully understood, but we are optimistic that our analysis here will help contextualize and show the implications for the emerging research on guilt.

\section{Acknowledgments}

We thank audiences at the University of Leuven, Georgetown University, and the University of Notre Dame, where an early version of this paper was presented. We also thank Robert Audi, Andreas De Block, Trip Glazer, Stefan Linquist, Jonathan Marks, Darcia Narvaez, Cailin O'Connor, Jay Odenbaugh, and two anonymous referees for their valuable comments on earlier 
This is a preprint of an article whose final and definitive form is published in Philosophical Psychology. Please quote only the published version, which is available online at: http://www.tandfonline.com/doi/full/10.1080/09515089.2015.1126706

drafts. This article was completed while one of us (Ramsey) was on a National Endowment for the Humanities-supported fellowship at at National Humanities Center. We thank the NEH and NHC for their support. Any views, findings, conclusions, or recommendations expressed in this article do not necessarily reflect those of the National Endowment for the Humanities.

\section{Notes}

${ }^{1}$ In giving an evolutionary account of guilt, we are not denying that the development and expression of guilt in humans is powerfully modulated by social and cultural contexts.

${ }^{2}$ For a helpful discussion of the conceptual issues involved in developing criteria for empirically differentiating guilt and shame, see Teroni and Deonna (2008).

${ }^{3}$ An evolutionary account of guilt also can contribute to functionalist approaches in psychology, which focus primarily on the social role played by guilt-induced behaviors (Tangney, 1996; Barrett, 1995; Estrada-Hollenbeck \& Heatherton, 1998).

${ }^{4}$ On positing similar psychological mechanisms underlying behavioral homologies across humans and other primates, see de Waal (2006). But cf. Sober (1993).

${ }^{5}$ While Frank offers two possible pathways for the evolution of social emotions like guilt, one based on reputation and the other on signaling, we focus on the latter. Frank's reputation account holds that a reputation for not cheating could have emerged as a means for reliably identifying individuals who experience moral sentiments. However, this would not explain why guiltproneness would have been favored specifically.

6 That the communication of information about the guilt-proneness of individuals may require advanced cognitive and linguistic capacities among humans does not entail that these same capacities would be required for communicating similar information among other primate groups. As we noted in section 3.2, the extant evidence is inconclusive as to whether a guilt-like mechanism is present in nonhuman primates, with scientists and philosophers in considerable disagreement as to how to interpret that evidence. Supposing other primates have guilt-like experiences, it is possible that information about those experiences is communicable to conspecifics through nonlinguistic means, such as the submission behaviors frequently exhibited by subordinates. 
This is a preprint of an article whose final and definitive form is published in Philosophical Psychology. Please quote only the published version, which is available online at:

http://www.tandfonline.com/doi/full/10.1080/09515089.2015.1126706

\section{References}

Amodio, D. M., Devine, P. G., \& Harmon-Jones, E. (2007). A dynamic model of guilt implications for motivation and self-regulation in the context of prejudice.

Psychological Science, 18, 524-530.

Averill, P. M., Diefenbach, G. J., Stanley, M. A., Breckenridge, J. K., \& Lusby, B. (2002).

Assessment of shame and guilt in a psychiatric sample: A comparison of two measures. Personality and Individual Differences, 32, 1365-1376.

Barrett, K. C. (1995). A functionalist approach to shame and guilt. In J. P. Tangney \& K. W. Fisher (Eds.), Self-conscious emotions: The psychology of shame, guilt, embarrassment, and pride (pp. 25-63). New York: Guilford Press.

--- (1998). The origins of guilt in early childhood. In J. Bybee (Ed.), Guilt and children (pp. 75-90). San Diego, CA: Academic Press.

Baumeister, R. F., Stillwell, A. M, \& Heatherton, T. F. (1994). Guilt: An interpersonal approach. Psychological Bulletin, 115, 243-267.

Bibas, S., \& Bierschbach, R. A. (2004). Integrating remorse and apology into criminal procedure. Yale Law Journal, 114, 85-148.

Boehm, C. (2012). Moral origins: The evolution of virtue, altruism, and shame. New York: Basic Books.

Bornstein, B. H., Rung, L. M., \& Miller, M. K. (2002). The effects of defendant remorse on mock juror decisions in a malpractice case. Behavioral Sciences \& the Law, 20, 393409.

Bybee, J., \& Quiles, Z. N. (1998). Guilt and mental health. In J. Bybee (Ed.), Guilt and children (pp. 269-291). San Diego, CA: Academic Press.

Call, J. \& Tomasello, M. (2008). Does the chimpanzee have a theory of mind? 30 Years Later. Trends in Cognitive Sciences, 12, 187-192.

Carlsmith, J. M., \& Gross, A. E. (1969). Some effects of guilt on compliance. Journal of Personality and Social Psychology, 11, 232-239.

Cheney, D. L., \& Seyfarth, R. M. (2007). Baboon metaphysics: The evolution of a social mind. Chicago: University of Chicago Press.

Coe, C. L., \& Rosenblum, L. A. (1984). Male dominance in the bonnet macaque: A malleable relationship. In P. Barchas \& S. Mendoza (Eds.), Social cohesion: Essays 
This is a preprint of an article whose final and definitive form is published in Philosophical Psychology. Please quote only the published version, which is available online at:

http:/www.tandfonline.com/doi/full/10.1080/09515089.2015.1126706

toward a sociophysiological perspective (pp. 31-64). Westport, CT: Greenwood Press.

Cohen, T. R., Panter, A. T., \& Turan, N. (2012). Predicting counterproductive work behavior from guilt-proneness. Journal of Business Ethics, 114, 45-53.

Cohen, T. R., Wolf, S. T., Panter, A. T., \& Insko, C. A. (2011). Introducing the GASP scale: A new measure of guilt and shame proneness. Journal of Personality and Social Psychology, 100, 947-966.

Cox, M. (1999). Remorse and reparation: “To double business bound.” In M. Cox (Ed.), Remorse and reparation (pp. 9-18). London: Jessica Kingsley.

Darby, B.W., \& Schlenker, B. R. (1989). Children's reactions to transgressions: Effects of the actor's apology, reputation and remorse. British Journal of Social Psychology, 28, $353-364$.

de Waal, F. (1996). Good natured: The origins of right and wrong in humans and other animals. Cambridge, MA: Harvard University Press.

--- (2006). Primates and philosophers: How morality evolved. Princeton, NJ: Princeton University Press.

Eisenberg, T., Garvey, S. P., \& Wells, M. T. (1998). But was he sorry?: The role of remorse in capital sentencing. Cornell Law Review, 83, 1599-1637.

Ekman, P., Levenson, R. W., \& Friesen, W. V. (1983). Autonomic nervous system activity distinguishes among emotions. Science, 221, 1208-1210.

Estrada-Hollenbeck, M., \& Heatherton, T. F. (1998). Avoiding and alleviating guilt through prosocial behavior. In J. Bybee (Ed.), Guilt and children (pp. 215-231). San Diego, CA: Academic Press.

Ferguson, T. J., Brugman, D., White, J., \& Eyre, H. L. (2007). Shame and guilt as morally warranted experiences. In J. L. Tracy, R. W. Robins, \& J. P. Tangney (Eds.), The selfconscious emotions: Theory and research (pp. 330-348). New York: Guilford Press.

Ferguson, T. J., Stegge, H., \& Damhuis, I. (1997) Children's understanding of guilt and shame. Child Development, 62, 827-839.

Fessler, D. M. T. (2007). From appeasement to conformity: Evolutionary and cultural perspectives on shame, competition, and cooperation. In J. L. Tracy, R. W. Robins \& J. P. Tangney (Eds.), The self-conscious emotions: Theory and research (pp. 174-193). New York: Guilford Press. 
This is a preprint of an article whose final and definitive form is published in Philosophical Psychology. Please quote only the published version, which is available online at:

http://www.tandfonline.com/doi/full/10.1080/09515089.2015.1126706

Fessler, D. M. T., \& Gervais, M. (2010). From whence the captains of our lives: Ultimate and phylogenetic perspectives on emotions in humans and other primates. In P. Kappeler \& J. B. Silk (Eds.), Mind the gap: The origins of human universals (pp. 261-280). Heidelberg: Springer.

Fessler, D. M. T., \& K. J. Haley. (2003). The strategy of affect: Emotions in human cooperation. In P. Hammerstein (Ed.), Genetic and cultural evolution of cooperation (pp. 7-36). Cambridge, MA: MIT Press.

Frank, R. H. (1988). Passions within reason. New York: W.W. Norton.

--- (2001). Cooperation through emotional commitment. In R. M. Neese (Ed.), Evolution and the capacity for commitment (pp. 57-76). New York: Russell Sage Foundation.

Garvey, S. P. (1998). Aggravation and mitigation in capital cases: What do jurors think? Columbia Law Review, 98, 1538-1576.

Gold, G. J., \& Weiner, B. (2000). Remorse, confession, group identity, and expectancies about repeating a transgression. Basic and Applied Social Psychology, 22, 291-300.

Hanson, R. K. \& Bussière, M. T. (1998). Predicting relapse: A meta-analysis of sexual offender recidivism studies. Journal of Consulting and Clinical Psychology, 66, 348362.

Harder, D. W. (1995). Shame and guilt assessment, and relationships of shame- and guiltproneness in psychopathology. In J. P. Tangney, \& K. W. Fischer (Eds.), Self-conscious emotions: The psychology of shame, guilt, embarrassment, and pride (pp. 368-392). New York: Guilford Press.

Harder, D. W., \& Zalma, A. (1990). Two promising shame and guilt scales: A construct validity comparison. Journal of Personality Assessment, 55, 729-745.

Harmon-Jones, E., Amodio, D. M., \& Zinner, L. R. (2007). Social psychological methods of emotion elicitation. In J. A. Coan \& J. J. B. Allen (Eds.), Handbook of emotion elicitation and assessment (pp. 91-105). Oxford: Oxford University Press.

Harrel, W. A. (1981). The effects of alcohol use and offender remorsefulness on sentencing decisions. Journal of Applied Social Psychology, 11, 83-91.

Harris, P. L. (1989). Children and emotion: The development of psychological understanding. Oxford: Blackwell.

Hemphill, J. F., Hare, R. D., \& Wong, S. (1998). Psychopathy and recidivism: A review. 
This is a preprint of an article whose final and definitive form is published in Philosophical Psychology. Please quote only the published version, which is available online at:

http://www.tandfonline.com/doi/full/10.1080/09515089.2015.1126706

Legal and Criminological Psychology, 3, 139-170.

Hosser, D., Windzio, M., \& Greve, W. (2008). Guilt and shame as predictors of recidivism: A longitudinal study with young prisoners. Criminal Justice and Behavior, 35, 138152.

Jehle, A., Miller, M. K., \& Kemmelmeier, M. (2009). The influence of accounts and remorse on mock jurors' judgments of offenders. Law and Human Behavior, 33, 393-404.

Joyce, R. (2006). The evolution of morality. Cambridge, MA: MIT Press.

Kaneko, T., \& Tomonaga, M. (2011). The perception of self-agency in chimpanzees (Pan troglodytes). Proceedings of the Royal Society B: Biological Sciences, 278, 3694-3702.

Katchadourian, Herant (2010). Guilt: The bite of conscience. Stanford, CA: Stanford University Press.

Keltner, D. (1995). Signs of appeasement: Evidence for the distinct displays of embarrassment, amusement, and shame. Journal of Personality and Social Psychology, $68,441-454$.

Keltner, D., \& Buswell, B. N. (1996). Evidence for the distinctness of embarrassment, shame, and guilt: A study of recalled antecedents and facial expressions of emotions. Cognition and Emotion 10, 155-171.

Keltner, D., \& Harker, L. A. (1998). The forms and functions of the nonverbal signal of shame. In P. Gilbert \& B. Andrews (Eds.), Shame: Interpersonal behavior, psychopathology, and culture (pp. 78-98). Oxford: Oxford University Press.

Ketelaar, T., \& Au, W. T. (2003). The effects of feelings of guilt on the behaviour of uncooperative individuals in repeated social bargaining games: An affect-as-information interpretation of the role of emotion in social interaction. Cognition and Emotion, 17, $429-453$.

Ketelaar, T. \& Clore, G. L. (1997). Emotion and reason: The proximate effects and ultimate functions of emotions. In G. Matthews (Ed.), Cognitive science perspectives on personality, emotion, and cognitive science (pp. 355-396). Amsterdam: Elsevier.

Kochanska, G., \& Aksan, N. (2006). Children's conscience and self-regulation. Journal of Personality, 74, 1587-1618.

Kochanska, G., Gross, J. N., Lin, M., \& Nichols, K. E. (2002). Guilt in young children: Development, determinants, and relations with a broader system of standards. Child 
This is a preprint of an article whose final and definitive form is published in Philosophical Psychology. Please quote only the published version, which is available online at:

http:/www.tandfonline.com/doi/full/10.1080/09515089.2015.1126706

Development, 73, 461-482.

Krebs, D. (2011). The origins of morality: An evolutionary account. Oxford: Oxford University Press.

Lagattuta, K. H., \& Thompson, R. A. (2007). The development of self-conscious emotions: Cognitive processes and social influences. In J. L. Tracy, R. W. Robins, \& J. P. Tangney (Eds.), The self-conscious emotions: Theory and research (pp. 91-113). New York: Guilford Press.

Leistico, A. R., Salekin, R. T., DeCoster, J., \& Rogers, R. (2008). A large-scale metaanalysis relating the hare measures of psychopathy to antisocial conduct. Law and Human Behavior, 32, 28-45.

Lewis, H. B. (1971). Shame and guilt in neurosis. New York: International Universities Press.

---. (1989). Some thoughts on the moral emotions of shame and guilt. In L. Cirillo, B. Kaplan \& S. Wapner (Eds.), Emotions in ideal human development (pp. 35-51). Hillsdale, N.J.: Lawrence Erlbaum, 1989.

Lindsay-Hartz, J., de Rivera, J., \& Mascolo, M. F. (1995). Differentiating guilt and shame and their effects on motivation. In J. P. Tangney \& K. W. Fischer (Eds.), Self-conscious emotions: The psychology of shame, guilt, embarrassment, and pride (pp. 274-300). New York: Guilford Press.

Luyten, P., Fontaine, J. R. J., \& Corveleyn, J. (2002). Does the Test of Self-Conscious Affect (TOSCA) measure maladaptive aspects of guilt and adaptive aspects of shame?: An empirical investigation. Personality and Individual Differences, 33, 1373-1387.

Malatesta, C. Z. (1990). The role of emotions in the development and organization of personality. In R. A. Thompson (Ed.), Socioemotional development: Nebraska Symposium on Motivation, 1998 (pp. 1-56). Lincoln, NE: University of Nebraska Press.

Malti, T., \& Krettenauer, T. (2013). The relation of moral emotion attributions to prosocial and antisocial behavior: A meta-analysis. Child Development, 84, 397-412.

Moll, J., de Oliveira-Souza, R. Zahn, R., \& Grafman, J. (2008). The cognitive neuroscience of moral emotions. In W. Sinnott-Armstrong (Ed.), Moral psychology, vol. 3 (pp. 3-17). Cambridge, MA: MIT Press.

Moore, M. S. (1987). The moral worth of retribution. In F. D. Schoeman (Ed.), 
This is a preprint of an article whose final and definitive form is published in Philosophical Psychology. Please quote only the published version, which is available online at:

http://www.tandfonline.com/doi/full/10.1080/09515089.2015.1126706

Responsibility, character, and the emotions: New essays in moral psychology (pp. 179219). Cambridge: Cambridge University Press.

Nunner-Winkler, G., \& B. Sodian (1988). Children's understanding of moral emotions. Child Development, 59, 1323-1338.

O’Connor, L. E. (2000). Pathogenic band guilt in human evolution: Implications for psychotherapy. In P. Gilbert \& K. G. Bailey (Eds.), Genes on the couch: Explorations in evolutionary psychotherapy (pp. 276-303). New York: Brunner-Routledge.

Okasha, S. (2006). Evolution and the levels of selection. New York: Oxford University Press.

Orleans, J. F., \& Gurtman, M. B. (1984). Effects of physical attractiveness and remorse on evaluations of transgressors. Academic Psychological Bulletin, 6, 49-56.

Panksepp, J., \& Biven, L. (2012). The archaeology of mind: Neuroevolutionary origins of human emotions. New York: W. W. Norton.

Porter, S., Brinke, L., \& Wilson, K. (2009). Crime profiles and conditional release performance of psychopathic and non-psychopathic sexual offenders. Legal and Criminological Psychology, 14, 109-118.

Regan, J. W. (1971). Guilt, perceived injustice, and altruistic behavior. Journal of Personality and Social Psychology, 18, 124-132.

Robinson, D. T., Smith-Lovin, L., \& Tsoudis, O. (1994). Heinous crime or unfortunate accident?: The effects of remorse on responses to mock criminal confessions. Social Forces, 73, 175-190.

Schaumberg, R. L., \& Flynn, F. J. (2012). Uneasy lies the head that wears the crown: The link between guilt proneness and leadership. Journal of Personality and Social Psychology, 103, 327-342.

Scherer, K. R. (1986). Vocal affect expression: A review and a model for future research. Psychological Bulletin, 99, 143-165.

Shin, L. M., Dougherty, D. D., Orr, S. P., Pitman, R. K., Lasko, M., Macklin, M. L., Alpert, N. M., Fischman, A. J., \& Rauch, S. L. (2000). Activation of anterior paralimbic structures during guilt-related script-driven imagery. Biological Psychiatry, 48, 43-50.

Silfver, M. (2007). Coping with guilt and shame: A narrative approach. Journal of Moral Education, 36, 169-183.

Sober, E. (1993). Evolutionary altruism, psychological egoism, and morality: Disentangling 
This is a preprint of an article whose final and definitive form is published in Philosophical Psychology. Please quote only the published version, which is available online at:

http:/www.tandfonline.com/doi/full/10.1080/09515089.2015.1126706

the phenotypes. In M. H. Nitticki \& D. V. Nitticki (Eds.), Evolutionary ethics (pp. 199216). Albany: State University of New York Press.

Sober, E., \& Wilson, D. S. (1998). Unto others: The evolution and psychology of unselfish behavior. Cambridge, MA: Harvard University Press.

Sterelny, K. (2003). Thought in a hostile world: The evolution of human cognition. Oxford: Blackwell.

Svensson, R., Weerman, F. M., Pauwels, L. J. R., Bruinsma, G. J. N. \& Bernasco, W. (2013). Moral emotions and offending: Do feelings of anticipated shame and guilt mediate the effect of socialization on offending? European Journal of Criminology, 10, 22-39.

Takahashi, H., Yahata, N., Koeda, M., Matsuda, T., Asai, K., \& Okubo, Y. (2004). Brain activation associated with evaluative processes of guilt and embarrassment: An fMRI study. NeuroImage, 23, 967-974.

Tangney, J. P. (1996). Conceptual and methodological issues in the assessment of shame and guilt. Behaviour Research and Therapy, 34, 741-754.

Tangney, J. P., Miller, R. S., Flicker, L., \& Barrow, D. H. (1996). Are shame, guilt, and embarrassment distinct emotions? Journal of Personality and Social Psychology, 70, $1256-1269$.

Teroni, F., \& Deonna, J. A. (2008). Differentiating shame from guilt. Consciousness and Cognition 17, 725-740.

Thompson, R. \& M. Hoffman (1980). Empathy and the development of guilt in children. Developmental Psychology, 16, 155-156.

Tracy, J. L., \& Robins, R. W. (2006). Appraisal antecedents of shame and guilt: Support for a theoretical model. Personality and Social Psychology Bulletin, 32, 1339-1351.

Van Vugt, E., Gibbs, J., Stams, G. J., Bijleveld, C., Hendriks, J., \& van der Laan, P. (2011). Moral development and recidivism: A meta-analysis. International Journal of Offender Therapy and Comparative Criminology, 55, 1234-1250.

Wallbott, H. G. (1998). Bodily expression of emotion. European Journal of Social Psychology, 28, 879-896.

Weisman, R. (2004). Showing remorse: Reflections on the gap between expression and attribution in cases of wrongful conviction. Canadian Journal of Criminology and Criminal Justice, 46, 121-138. 
This is a preprint of an article whose final and definitive form is published in Philosophical Psychology. Please quote only the published version, which is available online at:

http:/www.tandfonline.com/doi/full/10.1080/09515089.2015.1126706

Wicker, F. W., Payne, G. C., \& Morgan, R. D. (1983). Participant descriptions of guilt and shame. Motivation and Emotion, 7, 25-39.

Williams, G. C. (1966). Adaptation and Natural Selection. Princeton, NJ: Princeton University Press.

Zahn-Waxler, C., \& Kochanska, G. (1990). The origins of guilt. In R. A. Thompson (Ed.), Socioemotional development: Nebraska Symposium on Motivation, 1998 (pp. 183-258). Lincoln, NE: University of Nebraska Press. 